\title{
Trends in integrated land-use/transport modeling: An evaluation of the state of the art
}

\section{Rolf Moeckel}

Technical University of Munich

rolf.moeckel@tum.de

Ana T. Moreno Chou

Technical University of Munich

ana.moreno@tum.de

\author{
Carlos Llorca Garcia \\ Technical University of Munich \\ carlos.llorca@tum.de \\ Matthew Bediako Okrah \\ Technical University of Munich \\ matthew.okrah@tum.de
}

Abstract: Integrated land-use/transport models have five decades of history of both widely recognized successful implementations and implementations that remained far behind their originally stated goals. This paper summarizes the state of the art of integrated land-use/transport modeling and reports on findings from the Symposium for the Integration of Land-Use and Transport Models in Raitenhaslach, which is near Munich, in 2016. From these sources, the paper identifies major challenges in integrated land-use/transport modeling and proposes paths that support successful implementations. Particular attention is given to the coordination of short- and long-term decisions, the technical integration of models, microscopic versus macroscopic frameworks and appropriate levels of model complexity. The paper concludes with five themes that require further research to ensure that integrated landuse/transport models will keep up with modeling needs in the future.

\section{Article history:}

Received: April 10, 2017

Accepted: February 6, 2018

Available online: July 2, 2018

\section{Introduction}

The relevance of integrating land use with transportation analyses has been described since decades (Forrester, 1969). Many integrated land-use/transport models, however, remain in an early research exploration stage, many of which are abandoned after a few years due to high complexity or non-operationality. There is a renewed interest in overcoming the implementation issues, because new trends, such as telework or driverless vehicles, are expected to have substantial influence on land-use patterns. To fully reflect the impact of such trends, transport models cannot afford to leave the land-use forecast static but need to be integrated with land-use models.

This article identifies the most important issues in integrated land-use/transport modeling. This

Copyright 2018 Rolf Moeckel, Carlos Llorca, Ana T. Moreno \& Matthew Bediako Okrah

http://dx.doi.org/10.5198/jtlu.2018.1205

ISSN: 1938-7849 | Licensed under the Creative Commons Attribution - Noncommercial License 4.0

The Journal of Transport and Land Use is the official journal of the World Society for Transport and Land Use (WSTLUR) and is published and sponsored by the University of Minnesota Center for Transportation Studies. 
is based on two sources. First, a literature review provides an updated overview of the state of the art in integrated land-use/transport modeling (section 2). Secondly, findings from the Symposium for the Integration of Land-Use and Transport Models in Raitenhaslach, near Munich, held in November 2016, were summarized in this article (section 3). This paper attempts to summarize the main themes both from the literature and from discussions at the symposium and to draw some conclusions where the profession is likely to move in the near future (section 4).

\section{$2 \quad$ State of the art of integrated modeling}

Lowry's Model of Metropolis (Lowry, 1964) is often considered to be the first computer model that truly integrated land use and transportation. The Lowry Model assumed the location of basic employment exogenously and generated an equilibrium for the allocation of non-basic employment and population. Over the last five decades, this popular model has been implemented many times (e.g., Batty, 1976; Mishra, Ye, Ducca, \& Knaap, 2011; Wang, 1998). At least equally influential was Forrester's Theory of Urban Interactions (1969). Even though it was an aspatial model, his research on interactions between population, employment and housing has influenced the design of many spatial land-use models developed ever since.

The following state-of-the-art focuses on land-use models and their integration with transport models. Putman developed the Integrated Transportation and Land-Use model Package (ITLUP) (Putman, 1983), which led to the frequently applied DRAM and EMPAL models. Wilson's Entropy Model (1967) generated an equilibrium by maximizing entropy of trips, goods flows or the distribution of population.

The MEPLAN model developed by Echenique, Crowther, and Lindsay (1969) is an aggregated land-use transport model that used the basic concept of the Lowry model as a starting point. The model can simulate a variety of both land-use and transport scenarios. Another modeling approach using the Lowry model as a starting point is the TRANUS model (de la Barra \& Rickaby, 1982) that simulates land use, transport, and its interactions at the urban and regional scale.

Martínez (1996) developed a land-use model under the acronym MUSSA in which location choice is modeled as a static equilibrium. MUSSA used the bid-auction approach based on the bid-rent theory where consumers try to achieve prices as low as possible and not higher than their willingness to pay. In the bid-rent theory, first introduced by Alonso (1964: $36 \mathrm{ff}$.), land prices are the immediate result of the bid-auction process. In contrast, the discrete-choice approach -initially developed for housing choice by McFadden (1978: 76 ff.)- models land being bought or rented with no instant effect on the price.

Wegener (1982) developed the IRPUD model as a fully integrated land-use transport model. The household location choice is microscopic, simulating every household individually. The IRPUD model was one of the few early approaches that contradicted the common assumption that land-use models shall reach an equilibrium at the end of each simulation period. Land-use development aims at equilibrium constantly, but due to a continuously changing environment and slow reaction times of households, businesses, developers and planners, this equilibrium stage is never reached. The price of a new dwelling and the commute distance to the household's main workplace are accounted for as true constraints in location choice. Similarly, the Metroscope model for Portland, Oregon (Conder \& Lawton, 2002) compares expenditures for housing, transportation, food, health and all other expenses to ensure that household budgets are not exceeded.

PECAS (Hunt \& Abraham, 2003) is another land-use model that represents an equilibrium of competing demand for developable land. Households relocate based on available floorspace, prices, accessibilities and other location factors. PECAS combines this bid-rent approach in a spatial economic model with a microscopic land development model. DELTA (Simmonds, 1999) combines an economic 
model with households and job location model and a long-distance migration model.

Orcutt, Greenberger, Korbel, and Rivlin (1961: 45 ff.) proposed to simulate individuals, called microsimulation, rather than modeling population at the aggregate. A few influential microscopic landuse models have been developed, including the ILUTE (Miller \& Salvini, 2001), UrbanSim (Waddell, 2002), ALBATROSS (Arentze \& Timmermans, 2000), PUMA (Ettema, de Jong, Timmermans, \& Bakema, 2004), SimDELTA (Simmonds \& Feldman, 2007), TIGRIS XL (Geurs, Zondag, Jong, \& de Bok, 2013) and LUSDR (Gregor, 2006). All these models use an aggregate transport model. An exception is the ILUMASS model (Wagner \& Wegener, 2007). However, the microscopic integration between land use and transport never became operational. The probably first true integration of microsimulation land-use and transport models was developed by Waddell, Wang, Charlton, and Olsen (2010) for San Francisco. The model was able to use worker-specific travel times to work to feed the household relocation model instead of more aggregate accessibilities. This required to run the transport model every model year, which added substantial runtime. It resulted in an operational integration of the land-use and transportation models. In practical applications, however, aggregate accessibilities are used to reduce runtime.

Good overviews of operational land-use/transport models are given particularly by Kii, Nakanishi, Nakamura and Doi (2016), Acheampong and Silva (2015), Hunt, Kriger, and Miller (2005) and Wegener (2004, 2014). Since Ira Lowry developed his Model of Metropolis in the early 1960s, the integration of land use and transport has essentially remained unchanged. The land-use model provides the location of population and employment that are used in the transport model to generate travel demand. Conversely, the transport model provides zone-to-zone travel times that are used in the land-use model to calculate accessibilities that affect location choice of population and employment. This has been visualized in the famous land-use/transport feedback cycle shown in Figure 1. Details have improved over the last 50 years, but in practical applications, the land-use/transport integration methods remained unchanged. 


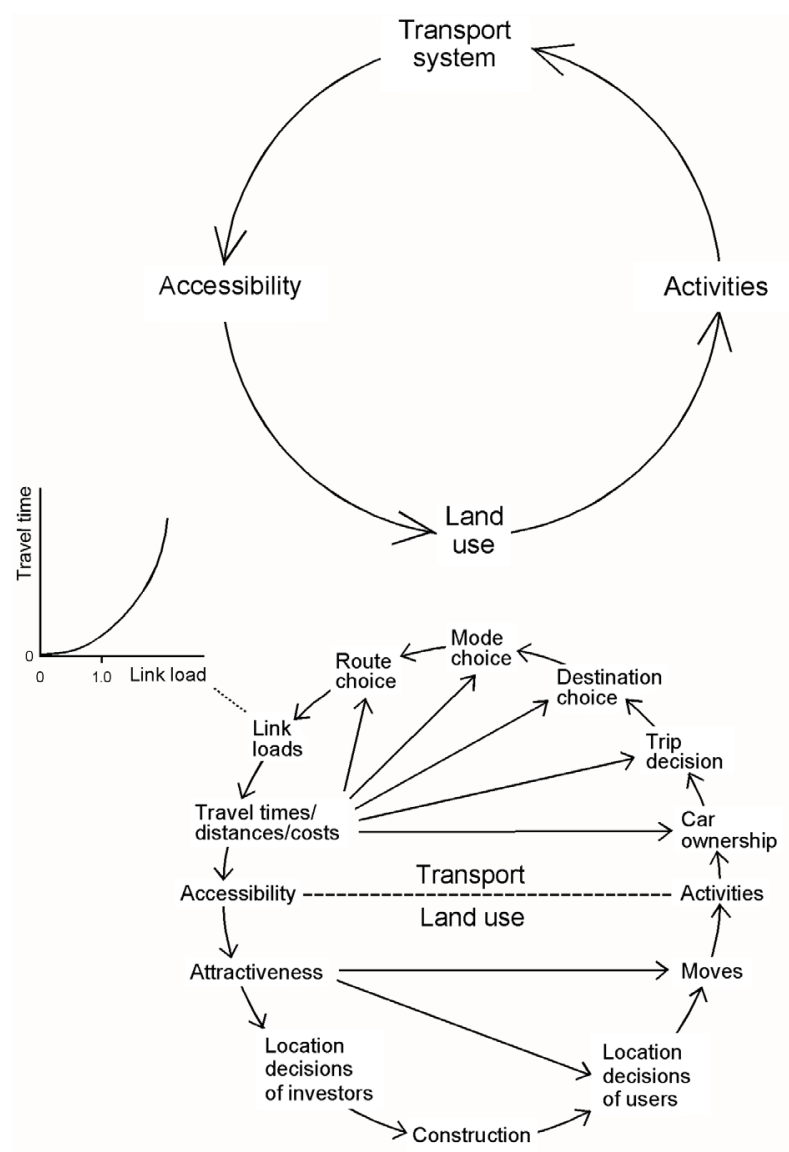

Figure 1: Land-use/transport feedback cycle (Wegener \& Fürst, 1999)

Nowadays, integrated models are used to analyze the impact of pricing scenarios, understand implications on equity issues and assess energy usage and environmental impacts. For such scenarios, the traditional feedback from land use to transport with aggregate accessibilities may not be sufficient. Kii et al. (2016) identified new requirements for integrated land-use/transport models to be climate change mitigation, energy scarcity, social conflicts, and new technologies such as autonomous vehicles or shared mobility services. Newer models may also call for more detail, such as the availability of telework or the capabilities of autonomous cars. At the same time, runtimes need to be limited to a reasonable amount of computing time. These new requirements of integrated land-use/transport models call for improved integration methods.

\section{$3 \quad$ Model development issues}

In response to the call for improved integration methods for land-use/transport models, a group of international experts in the domain of integrated land-use/transport modeling met in Raitenhaslach, near Munich, in November 2016 for a three-day symposium to discuss issues and future development of integrated land-use/transport models. During the presentations and discussions, four major themes dominated. These include the integration of decisions that cover different temporal scales, the technical integration of sub-models to facilitate transfer of data, the choice between microscopic and macroscopic 
models, as well as the level of complexity of models. The following subsections describe the themes in detail.

\subsection{Integration of short-term and long-term decisions}

Integrated land-use/transport modeling involves the simulation of a number of decisions covering different temporal scales. These include residential and work location choices, which are long term decisions, as well as activity participation, destination, mode and route choices which are short-term decisions. Simmonds, Waddell, and Wegener (2011) note that relocation of households and firms respond to changes only slowly because moves require substantial transaction costs. In between these temporal scales, there are other decisions like car ownership, which Paleti, Bhat, and Pendyala (2013) identified as medium term decisions. Using the concept of resources, Miller (2016) pointed out that short-term decisions are constrained by available resources whereas long-term decisions seek to change these resources over time. He identifies time budget as the major constraint in the short-term and emphasizes the importance of money budget in long-term decisions. Recognizing that almost all long-term decisions happen within a market process, Miller (2016) highlighted the need to model decisions related to residential or labor mobility within a market process.

While long-term decisions, such as residential location choice, influence daily travel behavior, being stuck in traffic everyday may influence the long-term decisions household relocation (as also expressed in Figure 1). Observing that long-term decisions happen at some point in time, Miller (2016) contended that understanding what triggers these long-term decisions and when they are triggered is central to build integrated land-use/transport models. He highlighted the concept of stress, which is the difference between the current and the expected or desired state, as a way to model the triggering of decisions. Decisions are triggered if stress exceeds a certain threshold. A major challenge, however, is to handle multiple stresses that influence multiple choices.

Despite the ordering of decisions between short- and long-run, Paleti et al. (2013) argued that there is little behavioral basis underlying such sequential decision frameworks. They contend that a number of short- and long-term choices are made jointly and call for the development of model systems where these choices are captured jointly. Using the computationally tractable maximum approximate composite marginal likelihood approach, they estimated a joint model system that simultaneously considered six different choice dimensions covering disparate temporal scales in a unifying framework.

\subsection{Technical integration of models}

A significant challenge of integrating land-use and transportation models is to ensure technical operationality. As both land-use and transport models by themselves tend to be sophisticated, the resulting integrated land-use/transport model will be necessarily complex. Commonly, long computation runtimes are the consequence. Some integrated land-use/transportation models reported runtimes of days for each scenario (Wegener, 2011), which provides a challenge for calibration, model updates and scenario analyses. In most cases, the longest runtime is found in the transportation submodel (especially when microscopic models are used for traffic assignment). In some cases (Shahumyan \& Moeckel, 2016; Wagner \& Wegener, 2007), traffic assignment represented 50\% of the runtime, even though the transportation submodels often are run less frequently (such as every 10 years) than the land-use submodels (such as every year). For the Munich metropolitan area, the traffic assignment of 1.7 million home-based-work trips in MATSim required 7 hours, providing a challenge if several years shall be modeled. One workaround is to sample agents for the traffic assignment simulation and to reduce the capacity of the network at the same time. This procedure, despite being commonly applied (Ziemke, 
Nagel, \& Bhat, 2015), has not been tested systematically. It is commonly asserted but unproven so far how realistic the prediction of delays and traffic volumes are when sampling is applied (Llorca, Moreno, Okrah, \& Moeckel, 2017).

To reduce run times of complex microscopic transportation models, several suggestions have been made. Tian and Chiu (2014) proposed improving traffic assignment models by adding additional learning algorithms for route choice (learning from assigned trips to increase speed when assigning new trips). Simmonds (2016) suggested to reduce levels of complexity and move towards a concept of "land-use models influenced by transportation" (LUMIT), or to substitute large-scale with simpler transport models. There is no general agreement on the maximum acceptable model runtime. On the one side, Wegener (2011) recommend 1 or 2 hours because (a) model developers need to run the models frequently for calibration and validation, and (b) models need to be run many times in application to cover a large range of scenarios. Others (Shahumyan \& Moeckel, 2016) recommend runtimes that do not exceed an overnight run (about 16 hours or less). It is argued that an overnight run balances the requirements of modeling detail with obtaining model results reasonably fast. Yet others have accepted longer run times in the interest of maintaining as much detail in the model as possible. The integrated model for Salt Lake City, Utah needs 2.5 to 3 days to complete a model run (Li \& Larson, 2017), and for Atlanta, Georgia the integrated model takes 5 days (Rosseau, 2017).

The integration of transportation and land-use models requires the exchange of data between modules that often were written by different developers and have different data structures. In the ideal case, all the modules should use open source licenses (Shahumyan \& Moeckel, 2016). Based on the data exchange frequency, the level of interaction goes from the manual integration (manually copying data files from one module to another module) to fully automated integration (no modeler intervention needed). To deal with diverse model structures and programming languages, the use of so-called wrappers (such as Python wrappers) may facilitate running each piece from a global environment.

Nagel (2016) goes further and strongly recommends the use of one single programming language for all submodules. A common language makes the exchange of data objects (such as agents, trips, coordinates, matrices, etc.) between modules much easier. This fact may facilitate the mutual communication not only between models, but also between modelers. The latter can be achieved by using developer tools such as Git (to share the code between different developers and organizations), Maven (to allow the installation of submodels as external dependencies or libraries) or Travis-CI (to run integration tests that analyze code for operationality and regression every time a change was checked in).

\subsection{Micro versus macro}

Wegener (2011) stated that the current trend in integrated land-use/transport models is the move towards multi-agent or activity-based models, where individual agents are simulated instead of aggregated units. Wegener explained this as a consequence of individualization of societies and the quest to better predict environmental issues, such as air quality or noise. The powerful and continuously increasing computational capacity could be an additional reason. At the same time, the microscopic representation might provide advantages for the integration of land use and transportation. For example, Moeckel and Nagel (2016) explained the benefit to use individual travel time to work of each household member instead of aggregated accessibilities to jobs when selecting a housing location. Donnelly, Erhardt, Moeckel, and Davidson (2010) note that the aggregation of microscopic data is always possible and fast, whereas the opposite (disaggregation) is rather difficult and sometimes impossible. Therefore, storing information as micro data adds flexibility to the integration of both aggregate and disaggregate models.

Simmonds (2016) confirmed the flexibility of micro data but only recommend microscopic approaches for research environments as a powerful tool to analyze agents' behavior. According to Sim- 
monds, model applications by practitioners should focus on simpler and faster macroscopic models to reduce runtimes. This notion is motivated in particular by the fact that some microsimulation models, such as ILUMASS (Wagner \& Wegener, 2007) or €LAN (Gertz, Maaß, \& Guimarães, 2015), never succeeded to become fully operational due to their levels of complexity.

Microscopic models present the additional challenge of stochastic variations for choice problems. Because these models rely on the generation of random numbers for so-called Monte Carlo simulations, the results after every run may be slightly different. The larger the number of choice alternatives, the stronger the stochastic variations in the results, especially when the model is applied to small populations (such as when the traffic assignment is based on a small part of the agents). Several runs might be required to calculate an average of the forecast results, as done by Donnelly (2009). Gregor (2006) stores several stochastic model runs on purpose as potential alternative futures. The required number of runs remains unknown and depends on the number of choices modeled and the number of alternatives in each choice set (Wegener, 2011).

Some authors proposed multi-level models that combine microscopic and macroscopic models. A common example is the traffic assignment for large networks, where network-wide macroscopic models are linked to microscopic models for the representation of certain interesting points, such as selected intersections (Kristofferson \& Engelson, 2016). Consequently, the propagation of delays at complex intersections can be modeled in detail, while areas of the network further away from the point of interest are not simulated at the same level of detail.

In contrast to the general trend of only using microsimulation in both transport and land-use modeling, Wegener (2011) proposed that the extent to which spatial units should be disaggregated depends on the planning task at hand. He states that there is an appropriate level of conceptual, spatial and temporal resolution for each planning problem. Wegener continues that models should be multi-level and multi-scale in terms of time, space and subsystems, incorporating both top-down and bottom-up feedback loops. For transport analyses, Ortúzar and Willumsen (2011) concluded that analyses of traffic management schemes generally requires smaller zones, while strategic studies benefit from using larger zones.

\subsection{Complex versus simple models}

While microscopic models tend to be more complex than macroscopic models, model complexity goes beyond the macro-micro debate and considers the number of variables as well as the degree of interaction among them. Similar to the trend towards microsimulation, the general direction of development has been to increase complexity. While there is general agreement that the model application should guide the level of complexity, it remains unclear when modelers should stop increasing the complexity and whether an optimum between complexity and simplicity can be identified.

On the one hand, increased complexities are caused by new variables in the models as a response to requirements for desired scenarios. For example, if policies need to be tested that affect pedestrians, a finer resolution of transportation zones may be necessary (Clifton, Singleton, Muhs, \& Schneider, 2016). Pedestrian route choice is particularly complex to model, as new additional variables related to the concept of walkability would be required. Similarly, the advent of autonomous vehicles and the introduction of vehicle sharing systems (Heinrichs, 2016), health impact modeling (Mueller et al., 2015) or the estimation of traffic-related emissions (Ruehr, 2016) call for additional complexity in the model.

A similar issue may be found in model estimation, where new data sources may provide more detailed information, and thereby, allow the use of additional attributes. According to De Vos, Mokhtarian, Schwanen, Van Acker, and Witlox (2016), the inclusion of behavioral aspects can improve the accuracy of choice predictions. For example, adding attitudinal aspects may improve the prediction in 
mode choice modelling. The use of some models, such as mixed logit models, can identify attitudes in the data, and subjects can be classified into attitudinal groups (car-friendly, transit-friendly, etc.). This has been shown to increase the model's goodness of fit (Malokin, Circella, \& Mokhtarian, 2015). Others (Axhausen, 2008; Carrasco \& Miller, 2006) argued that attitudes should go beyond the individual and be understood within the individual's social network. Long-term choices of its network members, such as home, workplace or regular meetings, can trigger travel demand that cannot be explained using generalized costs of travel or destination utility. Schönfelder and Axhausen (2016) also added monetary budgets to model estimation, as activity repertoires are based on the suitability and monetary costs of location for certain activities at certain times and for certain groups. However, the model estimation becomes more complicated. In addition, data requirements increase and are likely to limit transferability. The list of potential increases in model complexity is long. However, model developers need to be aware that complex models tend to have higher requirements for the model user. The education of the next generation of modelers need to keep up with complexity in modeling, and vice versa, model developers should account for the capability of future model users when deciding on complexity.

One possible approach in model development is to start with the most complex model possible in the development phase and simplify the model before completion of the research as much as possible. This approach will identify the best possible match of observed and modeled data. It will also specify the actual benefit of adding complexity. An alternative approach is to start with the simplest model possible and gradually increase complexity. This approach is called agile development in computer science (Donnelly, 2010; Martin, 2003) and has the fundamental benefit that the analyst has an operational (yet simple) model right from the beginning.

In general, more complex models usually are worth pursuing when scenarios with small impacts are tested (such as $2 \%$ rise of energy prices) to pick up minor changes in the system. Simpler models will often fulfil the need for more draconic scenarios (such as a 25\% energy prices rise or the complete ban of private cars from the city center).

\subsection{Policy sensitivities}

Integrated land-use/transport models may be built for two purposes. Some serve academic progress and aim at adding methodology or theory without the intent of solving immediately real-world problems, such as work on ILUMASS by Strauch et al. (2005). Others are highly applied and used to test policies to advise decision makers in transport and/or land-use planning, such as work by Conder and Lawton (2002); Hunt and Abraham (2003); Waddell (2000) and many others. Most models, however, do at least a little bit of both.

While it is acknowledged that scientific progress requires basic research, some models in the past suffered from being overly complex and never becoming operational (Wagner \& Wegener, 2007). As a consequence, some of these models contributed nothing to applied problem sets, and sometimes very little to scientific progress. In the 1970s, Lee Jr. (1973) warned of fundamental flaws of large scale modeling and suggested that planners should abandon modeling as a decision-support tool. Since then, many modeling systems have proven Lee wrong. A model like MEPLAN has been used many dozen times for scenario analysis (Hunt et al., 2005). Several integrated land-use/transport models have been used successfully in policy advise, both for transportation and land-use scenarios (Moeckel, forthcoming).

It seems that models that reached an operational status have been more influential, not only in policy advising but also in scientific progress. The summary papers cited in section 2 only list models that became operational and have at least the potential to advise policy makers. Models that do reach an operational status gain credibility, as results can be compared actual development and the reasonability of forecasts can be assessed. 


\section{Conclusions: Challenges ahead}

Since Lowry (1964) published his seminal Model of Metropolis more than 50 years ago, substantial progress has been made in integrated land-use/transport modeling. Discrete choice and bid-rent approaches have added theoretical foundations to model land-use decisions, and activity-based travel demand models as well as microscopic traffic assignments have augmented the possibilities in modeling detailed scenarios greatly. Despite some failed attempts to integrate land-use and transport models (which were to be expected in science), many integrated models work remarkably well. Such models have both provided material for successful research project and have proven to be useful as a planning instrument supporting decision makers.

However, there still remain challenges to integrated land-use/transport modeling and their application in practice. In a recent review and reflection of integrated models, Waddell (2011) identifies the theoretical and empirical realism of models, their computation performance, flexibility, transparency and ease of use as some of the key challenges facing integrated modeling and their application in practice. Based on the literature review, results from the symposium in Raitenhaslach in November 2016 and ongoing discussions with colleagues, a few important challenges of integrated land-use/transport modeling have been identified.

(1) Data storage and exchange formats. As identified in section 3.3, there is a trend towards microsimulation in integrated land-use/transport modeling. To improve collaboration, common ways to store and share micro data should be defined. For geospatial data, the ESRI Shapefile has been established as the standard format to store data. A white paper (ESRI, 1998) provides specifications that allow sharing shapefiles across platforms and softwares. For matrices, a similar standard was defined using the open source OMX matrix specification (Stabler, 2017). There is no such standard for storing and sharing micro data or synthetic populations. Developing such a standard would facilitate to work collaboratively with micro data across different study areas and softwares.

(2) Open source modeling frameworks. An open source framework is needed for integrated land-use/ transport modeling (compare section 3.2). OPUS (Open Platform for Urban Simulation) (Waddell, Borning, Ševíková, \& Socha, 2006) was an attempt to create an open source platform for land-use, activity-based and dynamic traffic assignment models. Even though some implementations in the U.S. and Europe were built using OPUS (Waddell, Wang, \& Liu, 2008; Waddell, Wang, Sevcikova, \& Borning, 2015), it was not used widely. Currently, OPUS is further developed to the Urban Data Science Toolkit (UDST), a promising alternative by the UrbanSim community that hosts various models and analysis tools. In comparison to OPUS, UDST advances coding practices and simplifies its implementation (https://github.com/UDST/urbansim). MATSim (Horni, Nagel, \& Axhausen, 2016) is a powerful model for dynamic traffic assignment that is applied in more than 40 study areas. Key to MATSim's success is its open-source license and flexible yet efficient implementation in code. ActivitySim (http://udst. github.io/activitysim/) is a promising alternative open source framework for activity-based models, as is VisionEval (https://gregorbj.github.io/VisionEval/) for sketch-planning models. Those are still in their infancy, but have the potential to become the standard for activity-based and sketch-planning modeling, respectively. The modeling community should strive to develop a similar framework for land-use modeling that rather seamlessly integrates with a variety of transport models.

(3) Model documentation and tutorials. For most model applications, the only successful model implementations were done or advised by the original model developer (or someone working closely

with the model developer). As a consequence, most models seem to disappear once the model developer retires or loses interest in maintaining the model. As discussed in section 3.4, many models are too complex, documentation is sparse at best, and model design tends to be too inflexible to account for different 
modeling requirements without major surgery of the source code. Tools to visualize model output (and thereby, to better understand model performance) are rare. The responsibility of the modeling community will be to develop, document and support models that are documented, agile and transferable.

(4) Education. Closely related is the responsibility of universities to educate graduates who are capable of understanding integrated models and interested in working with them (compare section 3.4). A recent survey among 70 U.S. transportation planning agencies revealed that $64 \%$ of those operating an integrated land-use/transport model are concerned that they do not have sufficient staff with adequate training to work with these models (Moeckel, forthcoming). Universities must help educating future champions of integrated modeling. Agencies, on the other hand, have the responsibility to give champions the opportunity to move applications of integrated models to the next level.

(5) Extensibility. It is widely accepted that models need to be designed for the scenarios that need to be analyzed (compare section 3.5). A model used predominantly for environmental analysis has different model specifications, a different spatial resolution and requires different input data than a model used for highway expansion analyses. As such, a model will never be able to handle every scenario well. In particular, future requirements of models are at least in part unknown today. An unresolved challenge for model developers is to build models that are tailored to the task at hand but allow flexible adjustments to new requirements. Only recently, the majority of transportation models were asked to model the impact of autonomous vehicles, despite the fact that this scenario was not even considered possible when many of these models were built. Microsimulation has the promise to facilitate flexible adjustments of the model to future (and currently unknown) challenges (compare section 3.3). Such models provide agents to be modeled at the finest resolution possible, and thereby, allow aggregation to any level needed for future model extensions. This will be an important strategy to keep models relevant in a changing environment.

While important progress has been made in integrated land-use/transport models over the last few decades, this field of research has a fair share of attempts to integrate land use with transport models that did not succeed to create operational models. This is not uncommon in research, as scientific progress can be achieved with both successful implementations and models that do not reach maturity. The latter may have relevance in two regards. On the one hand, scientific progress may have been achieved in submodels, even if the entire model system has not become operational. On the other hand, a model implementation that did not work out well may provide lessons learned for future model development. However, models that become operational serve not only the model developer communities but also scenario analyses. In 1973, Lee Jr. (1973) wrote the infamous article on the failure of large scale models that never reached maturity for scenario analysis. While scientific progress can be made with research that falls short of its original goals, researchers working on integrated land-use/transport models will continuously need to proof to be relevant. Having an eye on operationality will help to proof the value of integrated land-use/transport modeling both to the scientific community and to those who apply models.

\section{Acknowledgement}

The research was completed with the support of the Technische Universität München - Institute for Advanced Study, funded by the German Excellence Initiative and the European Union Seventh Framework Programme under grant agreement $n^{\circ} 291763$. The research was also supported by the TUM University Foundation Fellowship (TUFF) for international postdocs. 


\section{References}

Acheampong, R. A., \& Silva, E. (2015). Land use-transport interaction modeling: A review of the literature and future research directions. Journal of Transport and Land Use, 8(3), 11-38. doi:10.5198/ jtlu.2015.806

Alonso, W. (1964). Location and land use. Towards a general theory of land rent. Cambridge, Massachusetts: Harvard University Press.

Arentze, T., \& Timmermans, H. (2000). ALBATROSS - A learning based transportation oriented simulation system. Eindhoven: European Institute of Retailing and Services Studies.

Axhausen, K. W. (2008). Social networks, mobility biographies, and travel: Survey challenges. Environment and Planning B: Planning and Design, 35(6): 981-996. https://doi.org/10.1068/b3316t

Batty, M. (1976). Urban modelling. Algorithms, calibrations, predictions (Vol. 3). London: Cambridge University Press.

Carrasco, J. A., \& Miller, E. J. (2006). Exploring the propensity to perform social activities: A social network approach. Transportation, 33(5), 463-480. doi:10.1007/s11116-006-8074-z

Clifton, K. J., Singleton, P. A., Muhs, C. D., \& Schneider, R. J. (2016). Representing pedestrian activity in travel demand models: Framework and application. Journal of Transport Geography, 52, 111-122. doi:10.1016/j.jtrangeo.2016.03.009

Conder, S., \& Lawton, K. (2002). Alternative futures for integrated transportation and land-use models contrasted with trend-delphi models. Transportation Research Record: Journal of the Transportation Research Board, 1805, 99-107.

de la Barra, T., \& Rickaby, P. A. (1982). Modelling regional energy-use: A land-use, transport, and energy-evaluation model. Environment and Planning B: Planning and Design, 9(4), 429-443.

De Vos, J., Mokhtarian, P. L., Schwanen, T., Van Acker, V., \& Witlox, F. (2016). Travel mode choice and travel satisfaction: Bridging the gap between decision utility and experienced utility. Transportation, 43(5), 771-796. doi:10.1007/s11116-015-9619-9

Donnelly, R. (2009). A hybrid microsimulation model of urban freight transport demand. (Doctorate doctoral thesis), University of Melbourne, Melbourne.

Donnelly, R. (2010). Are your models agile, or fragile? Paper presented at the TRB Innovations in Travel Modeling, Tempe, AZ.

Donnelly, R., Erhardt, G. D., Moeckel, R., \& Davidson, W. A. (2010). Advanced practices in travel

forecasting. Transportation Research Board of the National Academies, Washington, DC.

Echenique, M. H., Crowther, D., \& Lindsay, W. (1969). A spatial model of urban stock and activity. Regional Studies, 3, 281-312.

ESRI. (1998). ESRI shapefile technical description. Retrieved from https://www.esri.com/library/ whitepapers/pdfs/shapefile.pdf

Ettema, D., de Jong, K., Timmermans, H., \& Bakema, A. (2004, October). PUMA (Predicting urbanization with multi-agents): A multi-agent approach to modelling urban development and processes. Paper presented at the Integrated Assessment of the Land System: The future of land use, Amsterdam.

Forrester, J. W. (1969). Urban dynamics. Cambridge, Massachusetts: MIT Press.

Gertz, C., Maaß, J., \& Guimarães, T. (Eds.). (2015). Auswirkungen von steigenden Energiepreisen auf die Mobilität und Landnutzung in der Metropolregion Hamburg. Ergebnisse des Projektes $€ L A N$ - Energeipreisentwicklung und Landnutzung (Vol. 13). Hamburg: Monsenstein und Vannerdat OHG Münster.

Geurs, K., Zondag, B., Jong, G., \& de Bok, M. (2013). Accessibility appraisal of land-use/transport policy strategies: More than just adding up travel-time savings. Transportation Research, Part D: 
Transport and Environment, 15(7), 382-392

Gregor, B. (2006). The Land Use Scenario DevelopeR (LUSDR): A Practical land-use model using a stochastic microsimulation framework. Paper presented at the 86th Annual Meeting of the Transportation Research Board, Washington, DC.

Heinrichs, D. (2016). Autonomous driving and urban land use. In M. Maurer, J. C. Gerdes, B. Lenz, \& H. Winner (Eds.), Autonomous driving: Technical, legal and social aspects (pp. 213-231). Berlin, Heidelberg: Springer Berlin Heidelberg.

Horni, A., Nagel, K., \& Axhausen, K. W. (Eds.). (2016). The multi-agent transport simulation MATSim. London: Ubiquity Press.

Hunt, J. D., \& Abraham, J. E. (2003). Design and application of the PECAS land-use modelling system. Paper presented at the 8th International Conference on Computers in Urban Planning and Urban Management, Sendai, Japan.

Hunt, J. D., Kriger, D. S., \& Miller, E. J. (2005). Current operational urban land-use-transport modelling frameworks: A review. Transport Reviews, 25(3), 329-376.

Kii, M., Nakanishi, H., Nakamura, K., \& Doi, K. (2016). Transportation and spatial development: An overview and a future direction. Transport Policy, 49, 148-158. doi:http://doi.org/10.1016/j. tranpol.2016.04.015

Kristofferson, I., \& Engelson, L. (2016). Estimating preferred departure times of road users in a large urban network. Transportation, in press, 1-21. doi:10.1007/s11116-016-9750-2

Lee Jr., D. B. (1973). Requiem for large-scale models. Journal of the American Institute of Planners, 39(3), $163-178$.

Li, A., \& Larson, J. (2017, March) Phone interview with the Wasatch Front Regional Council on integrated land-use/transport modeling. Interviewer: R. Moeckel.

Llorca, C., Moreno, A., Okrah, M., \& Moeckel, R. (2017). Traffic assignment for an integrated land- use and transportation model in a large metropolitan area: Case study of Munich. Paper presented at the 6th Symposium of the European Association for Research in Transportation (hEART 2017), Haifa, Israel.

Lowry, I. S. (1964). A model of metropolis. Memorandum RM-4035-RC. Santa Monica: Rand Corporation.

Malokin, A., Circella, G., \& Mokhtarian, P. L. (2015). How do activities conducted while commuting influence mode choice? Paper presented at the 94th Annual Meeting of the Transportation Research Board, Washington, DC.

Martin, R. C. (2003). Agile software development: Principles, patterns, and practices. Upper Saddle River, NJ: Prentice Hall PTR.

Martínez, F. J. (1996). MUSSA: Land-use model for Santiago City. Transportation Research Record, $1552,126-134$.

McFadden, D. (1978). Modelling the choice of residential location. In A. Karlqvist, L. Lundqvist, F. Snickars, \& J. W. Weibull (Eds.), Spatial interaction theory and planning models (pp. 75-96). Amsterdam: North-Holland Publishing Company.

Miller, E. J. (2016). Integrating short- and long-run decisions: Past lessons \& future prospects. Symposium for the Integration of Land-Use and Transport Models. Raitenhaslach, Germany.

Miller, E. J., \& Salvini, P. A. (2001). The integrated land use, transportation, environment (ILUTE) microsimulation modelling system: Description and current status. In D. A. Hensher (Ed.), Travel behavior research. The leading edge (pp. 711-724). Amsterdam: Pergamon.

Mishra, S., Ye, X., Ducca, F., \& Knaap, G.-J. (2011). A functional integrated land-use/transportation model for analyzing transportation impacts in the Maryland-Washington, DC, region. Sustainabil- 
ity: Science, Practice, \& Policy, 7(2), 60-69.

Moeckel, R. (forthcoming). Integrated transportation and land-use models. NCHRP Synthesis Report. National Academies of Sciences: Washington, D.C.

Moeckel, R., \& Nagel, K. (2016). Maintaining mobility in substantial urban growth futures. Transportation Research Procedia, 19, 70-80. doi:http://dx.doi.org/10.1016/j.trpro.2016.12.069

Mueller, N., Rojas-Rueda, D., Cole-Hunter, T., de Nazelle, A., Dons, E., Gerike, R., Götschi, T., Int Panis, L., Kahlmeier, S., \& Nieuwenhuijsen, M. (2015). Health impact assessment of active transportation: A systematic review. Preventive Medicine, 76, 103-114. doi:http://dx.doi.org/10.1016/j. ypmed.2015.04.010

Nagel, K. (2016). Using MATSim as a travel model plugin to SILO: Why this time we will get it right. Symposium for the Integration of Land-Use and Transport Models. Raitenhaslach, Germany.

Orcutt, G. H., Greenberger, M., Korbel, J., \& Rivlin, A. M. (1961). Microanalysis of socioeconomic systems: A simulation study. New York: Harper \& Brothers.

Ortúzar, J. d. D., \& Willumsen, L. G. (2011). Modelling transport (4th ed.). Chichester: John Wiley \& Sons.

Paleti, R., Bhat, C., \& Pendyala, R. M. (2013). Integrated model of residential location, work location, vehicle ownership, and commute tour characteristics. Transportation Research Record: Journal of the Transportation Research Board, 2382, 162-172.

Putman, S. H. (1983). Integrated urban models. Policy analysis of transportation and land use (Vol. 10). London: Pion.

Rosseau, G. (2017, January) Phone interview with the Atlanta Regional Council on integrated landuse/transport modeling. Interviewer: R. Moeckel.

Ruehr, E. (2016). Farewell to level of service? California's efforts to create a more environmentally-friendly performance measure. Paper presented at the International Symposium on Enhancing Highway Performance, Berlin.

Schönfelder, S., \& Axhausen, K. W. (2016). Urban rhythms and travel behavior. Spatial and temporal phenomena of daily travel. Abingdon, UK: Routledge.

Shahumyan, H., \& Moeckel, R. (2016). Integration of land use, land cover, transportation, and environmental impact models: Expanding scenario analysis with multiple modules. Environment and Planning B: Planning and Design. doi:10.1177/0265813516647062

Simmonds, D., Waddell, P., \& Wegener, M. (2011). Equilibrium vs. dynamics in urban modelling. Enviornment and Planning B: Urban Analytics and City Science, 40(6), 1051-1070.

Simmonds, D. C. (1999). The design of the DELTA land-use modelling package. Environment and Planning B: Planning and Design, 26(5), 665-684.

Simmonds, D. C. (2016). Transport modelling, microsimulation and other issues in land-use/economic/transport modelling practice. Symposium for the Integration of Land-Use and Transport Models. Raitenhaslach, Germany.

Simmonds, D. C., \& Feldman, O. (2007). Advances in integrated urban/regional land-useltransport modelling using the DELTA package. Paper presented at the World Conference on Transport Research (WCTR), Berkeley, CA.

Stabler, B. (2017). Open matrix. Retrieved from https:/github.com/osPlanning/omx/wiki

Strauch, D., Moeckel, R., Wegener, M., Gräfe, J., Mühlhans, H., Rindsfüser, G., \& Beckmann, K. J. (2005). Linking transport and land-use planning: The microscopic dynamic simulation model ILUMASS. In P. M. Atkinson, G. M. Foody, S. E. Darby, \& F. Wu (Eds.), GeoDynamics (pp. 295-311). Boca Raton: CRC Press.

Tian, Y., \& Chiu, Y.-C. (2014). A computational efficient approach to retaining zone pair travel time information in dynamic traffic assignment for activity-based model integration. Paper presented at the 93rd Annual Meeting of the Transportation Research Board, Washington, DC. 
Waddell, P. (2000). A behavioral simulation model for metropolitan policy analysis and planning: Residential location and housing market components of UrbanSim. Environment and Planning B: Planning and Design, 27(2), 247-263.

Waddell, P. (2002). UrbanSim. Modeling urban development for land use, transportation, and environmental planning. Journal of the American Planning Association, 68(3), 297-314.

Waddell, P. (2011). Integrated land use and transportation planning and modelling: Addressing challenges in research and practice. Transport Reviews 31(2), 209-229. https://doi.org/10.1080/014416 47.2010.525671

Waddell, P., Borning, A., Ševíková, H., \& Socha, D. (2006). Opus (the open platform for urban simulation) and UrbanSim 4. Paper presented at the 7th Annual International Conference on Digital Government Research, San Diego, CA.

Waddell, P., Wang, L., Charlton, B., \& Olsen, A. (2010). Microsimulating parcel-level land use and activity-based travel: Development of a prototype application in San Francisco. Journal of Transport and Land Use, 3(2), 65-84. doi:10.5198/jtlu.v3i2.124

Waddell, P., Wang, L., \& Liu, X. (2008). UrbanSim: An evolving planning support system for evolving communities. In R. Brail (Ed.), Planning support systems (pp. 103-138). Cambridge, MA: Lincoln Institute for Land Policy.

Waddell, P., Wang, L., Sevcikova, H., \& Borning, A. (2015). Agile modeling: Adapting UrbanSim to the European context using the open platform for urban simulation. In M. Bierlaire, A. de Palma, \& P. Waddell (Eds.), Integrated transport and land-use modeling for sustainable cities (pp. 309-331). Abingdon, UK: Routledge and EPFL Press.

Wagner, P., \& Wegener, M. (2007). Urban land use, transport and environment models. Experiences with an integrated microscopic approach. disP, 170(3), 45-56.

Wang, F. (1998). Urban population distribution with various road networks: A simulation approach. Environment and Planning B: Planning and Design, 25, 265-278.

Wegener, M. (1982). Modeling urban decline: A multilevel economic-demographic model for the Dortmund Region. International Regional Science Review, 7(2), 217-241.

Wegener, M. (2004). Overview of land-use/transport models. In D. A. Hensher, K. J. Button, K. E. Haynes, \& P. R. Stopher (Eds.), Handbook of transport geography and spatial systems (Vol. 5, pp. 127-146). Amsterdam: Elsevier.

Wegener, M. (2011). From macro to micro- how much micro is too much? Transport Reviews, 31(2), 161-177. doi:10.1080/01441647.2010.532883

Wegener, M. (2014). Land-use transport interaction models. In M. Fischer \& P. Nijkamp (Eds.), Handbook of regional science (pp. 741-758). Berlin, Heidelberg: Springer.

Wegener, M., \& Fürst, F. (1999). Land-use transport interaction: State of the art. Berichte aus dem Institut für Raumplanung, Vol. 46. IRPUD: Dortmund.

Wilson, A. G. (1967). Statistical theory of spatial distribution models. Transportation Research, 1, $253-$ 269.

Ziemke, D., Nagel, K., \& Bhat, C. (2015). Integrating CEMDAP and MATSIM to increase the transferability of transport demand models. Transportation Research Record: Journal of the Transportation Research Board, 2493, 117-125. doi:10.3141/2493-13 